\title{
Quality of life of alcohol dependent patients attending a deaddiction centre in Kannur district
}

\author{
R. Ratheesh $^{1}$, Bindu Mohandas ${ }^{2}$, P. P. Venugopalan ${ }^{3}$, A. K. Sarada ${ }^{3}$, Suprej K. ${ }^{4}$, Sobith V. K. ${ }^{3}$
}

${ }^{1}$ Department of Pharmacology, ${ }^{2}$ Department of Community Medicine, KMCT Medical College, Calicut, Kerala, India ${ }^{3}$ Department of Community Medicine, Kannur Medical College, Anjarakandy, Kerala, India

${ }^{4}$ AIIMS Delhi, India

Received: 17 November 2019

Revised: 29 November 2019

Accepted: 03 December 2019

\section{*Correspondence:}

Dr. Bindu Mohandas,

Email: bindumohandas86@gmail.com

Copyright: (C) the author(s), publisher and licensee Medip Academy. This is an open-access article distributed under the terms of the Creative Commons Attribution Non-Commercial License, which permits unrestricted non-commercial use, distribution, and reproduction in any medium, provided the original work is properly cited.

\section{ABSTRACT}

Background: Quality of life (QOL) is individuals' perceptions of their position in life. QOL of alcohol dependent patients is an area that has received relatively less attention compared to other alcohol related problems.

Methods: A deaddiction centre based cross sectional study was done on 370 individuals using a predesigned questionnaire during the period of 2012-2013. The data was analyzed using SPSS version 17. Spearman's rank correlation test was used to find association between the study variables.

Results: The mean age of the study subjects was $38.08 \pm 8.46$ years. The mean duration of drinking was $12.62 \pm 7.47$ years. The overall score of the QOL and the perceived health in alcohol dependent patients was $3.19 \pm 0.89$ and $3.01 \pm 0.98$ respectively. The mean of the transformed scores of physical, psychological, social and environmental domains are $69.12 \pm 12.82,57.84 \pm 12.81,58.52 \pm 17.05,68.62 \pm 10.23$ respectively. Statistical analysis of age with physical, environmental and social domains showed a significant negative correlation; literacy status with QOL, perceived health, physical, psychological, social and environmental domains showed a significant positive correlation; socio economic status with QOL and psychological domain showed a significant positive correlation; duration of drinking with QOL, perceived health, physical and psychological domain showed a significant negative correlation.

Conclusions: Harm from alcohol use is a major public health problem. Reducing the level of social and health harms from alcohol requires preparation and planning.

Keywords: Alcohol, Deaddiction centre, Quality of life

\section{INTRODUCTION}

Alcoholic beverages have been known and used in human societies for thousands of years. ${ }^{1}$ Alcohol has been used in India for a very long time, but the amounts consumed and problems associated have increased in recent years. ${ }^{2}$ Societies have found a variety of uses for them, including foods, medicines, mood-changers and intoxicants, as well as social lubricants and emblems of social status. The World Health Organization (WHO) estimates on the global burden of disease (expressed in years of life lost due to death and disability, or "DALYs") demonstrate that alcohol causes morbidity and mortality on a level with measles and malaria and at a higher rate than tobacco. This shows the significance of alcohol's role in health and social well-being in today's world. ${ }^{1}$

According to WHO worldwide, an estimated 2.3 million people die from alcohol related causes. This is $3.7 \%$ of all deaths, $6.1 \%$ among men and $1.1 \%$ among women. Also, 
64.9 million DALYs are lost due to alcohol related causes. WHO has estimated that there are about 2 billion people worldwide who consume alcoholic beverages and 76.3 million with disorders arising out of harmful use of alcohol. ${ }^{3}$ From a public health perspective, the global burden related to alcohol consumption, both in terms of morbidity and mortality, is considerable in most parts of the world. Alcohol consumption is the leading risk factor for burden in low mortality developing countries and the third largest risk factor in developed countries. The impact of alcohol on physiological, physical, social, and mental health is a serious problem in India, exacerbated by the poor public health indices, access to health services and infrastructure. It has a heavy burden on the health of individuals, their families and societies. ${ }^{4}$

3,20,000 young people between the age of 15 and 29 die from alcohol-related causes, resulting in $9 \%$ of all deaths in that age group. Alcohol is the world's third largest risk factor for disease burden; it is the leading risk factor in the Western Pacific and the Americas and the second largest in Europe. Alcohol is associated with many serious social and developmental issues, including violence, child neglect and abuse, and absenteeism in the workplace. ${ }^{5}$ Alcohol is a causal factor in 60 types of diseases and injuries and a component cause in 200 others. Almost $4 \%$ of all deaths worldwide are attributed to alcohol. ${ }^{6}$ WHO has been ranking the countries of the Region based on average drinking patterns, currently India stands at $3^{\text {rd }}$ place (in 2004). There is now evidence that drinking is being initiated at progressively younger ages. The increasing production, distribution, promotion and easy availability of alcohol coupled with the changing values of society has resulted in alcohol-related problems emerging as a major public health concern in India. ${ }^{7}$ The National Household Survey in India reported that, of the 62.5 million alcohol-users in India, 10.6 million are dependent users. ${ }^{8}$ Kerala consumes more alcohol than any other state in India. Per capita consumption of alcohol in Kerala (in 2010) is 11.1 liters per person per year.

Quality of life (QOL) is defined by the WHO as 'individuals' perceptions of their position in life in the context of the culture and value systems in which they live and in relation to their goals, expectations, standards and concerns". It is a broad ranging concept incorporating in a complex way the persons' physical health, psychological state, level of independence, social relationships, personal beliefs and their relationships to salient features of the environment. It reflects the view that QOL refers to a subjective evaluation, which is embedded in a cultural, social and environmental context. The WHOQOL focuses upon respondents' "perceived" QOL, the perceived effects of disease and health interventions on the individual's QOL. The WHOQOL is, an assessment of a multi-dimensional concept incorporating the individual's perception of health status, psycho-social status and other aspects of life. ${ }^{10}$
QOL of alcohol dependent patients is an area that has received relatively less attention compared to other alcohol related problems. Although alcohol misuse is a major cause of morbidity and mortality and an important health care burden, the QOL of alcohol misusing subjects has been little studied to date. ${ }^{11}$ The present study was done to study the socio demographic profile and physical domain, social domain, psychological domain, and environmental domain of the QOL of the alcohol dependent patients attending deaddiction centre.

\section{METHODS}

A cross sectional study was carried out from March 2012 to February 2013. During this period patients came to the Pratheeksha deaddiction centre, Thalassery was considered for the study. A total sample of 370 individuals was obtained by convenient sampling. Data was collected using a self-structured questionnaire. Modified B J Prasad's classification was used to assess the socio-economic status of the patients studied. ${ }^{12}$ International classification of diseases tenth revision (ICD 10) was used for defining criteria of alcohol dependence. ${ }^{13}$ WHOQOL BREF instrument was used to assess the QOL. ${ }^{10}$ The WHOQOL BREF produces a quality of life profile. The WHOQOL focuses upon respondents' "perceived" QOL, the perceived effects of disease and health interventions on the individual's QOL. The instrument has 26 questions which incorporates four domains namely physical, psychological, social, and environmental; and each domain consists of 7, 6, 3, and 8 questions respectively. There are also two items that are examined separately: question 1 asks about an individual's overall perception of QOL and question 2 asks about an individual's overall perception of their health. The four domain scores denote an individual's perception of QOL in each particular domain. Domain scores are scaled in a positive direction (i.e. higher scores denote higher QOL).

Alcohol dependent patients who were admitted to the deaddiction centre, who fulfilled the inclusion criteria for alcohol dependence according to the ICD-10 classification of mental and behavioural disorders: clinical descriptions and diagnostic guidelines; and who gave written informed consent were recruited for the study. The data was analyzed using SPSS version 17. Spearman's rank correlation test was used to find association between the study variables.

\section{Ethical approval}

The study was conducted after obtaining the approval from the Institutional Ethics Committee and permission was sought from the authority of the Pratheeksha Deaddiction Centre, Thalassery. 


\section{RESULTS}

Out of the 370 male patients studied, the age of the study subjects ranged from 18 to 63 years. The mean age of the study subjects was $38.08 \pm 8.46$ years. The mean duration of drinking was $12.62 \pm 7.47$ years. The socio demographic details of the study participants are depicted in Table 1.

The median score of both the physical and the environmental domains were 69; and the median score of both the psychological and social domains were 56 . The transformed scores ranged from 31 to 100 in both physical and environmental domains, 13 to 94 in psychological domain, and 19 to 100 in social domain.

When age was correlated with QOL, perceived health, physical, psychological, social and environmental domains, it showed a significant negative correlation with physical, environmental and social domains. As age increased, the study subjects reported poor QOL, low scores in physical, environmental and social domain.

Literacy status when correlated with QOL, perceived health, physical, psychological, social and environmental domains, it showed a significant positive correlation with all these variables except for physical domain. As education status increased, the study subjects reported good scores in all these variables. When occupational status was analyzed with QOL, perceived health, physical, psychological, social and environmental domains, it showed a significant positive correlation with psychological domain.

Socioeconomic status when correlated with QOL, perceived health, physical, psychological, social and environmental domains, it showed a significant positive correlation to QOL and psychological domain. As the socioeconomic status increased, good scores were reported in all these variables.

Table 1: Socio demographic characteristics of study participants $(n=370)$.

\begin{tabular}{|c|c|c|}
\hline Socio demographic variables & Number & Percentage $(\%)$ \\
\hline \multicolumn{3}{|l|}{ Residence } \\
\hline Rural & 238 & 64.3 \\
\hline Urban & 132 & 35.7 \\
\hline \multicolumn{3}{|l|}{ Religion } \\
\hline Hindu & 214 & 57.84 \\
\hline Muslim & 44 & 11.89 \\
\hline Christian & 112 & 30.27 \\
\hline \multicolumn{3}{|l|}{ Education } \\
\hline Professional degree & 10 & 2.7 \\
\hline Postgraduate/graduate & 77 & 20.8 \\
\hline Pre degree & 77 & 20.8 \\
\hline High school & 161 & 43.5 \\
\hline Middle school & 42 & 11.4 \\
\hline Primary school & 3 & 0.8 \\
\hline \multicolumn{3}{|l|}{ Occupation } \\
\hline Professional & 10 & 2.7 \\
\hline Semi professional & 2 & 0.5 \\
\hline Clerk/shop owner/agriculture & 153 & 41.4 \\
\hline Skilled & 84 & 22.7 \\
\hline Semi skilled & 37 & 10 \\
\hline Unskilled & 77 & 20.8 \\
\hline Students & 7 & 1.9 \\
\hline \multicolumn{3}{|l|}{ Socioeconomic status } \\
\hline Class I & 37 & 10 \\
\hline Class II & 232 & 62.7 \\
\hline Class III & 96 & 25.9 \\
\hline Class IV & 5 & 1.4 \\
\hline Class V & 0 & 0 \\
\hline \multicolumn{3}{|l|}{ Marital status } \\
\hline Married & 281 & 75.9 \\
\hline Unmarried & 71 & 19.2 \\
\hline Separated & 11 & 3 \\
\hline Divorced & 3 & 0.8 \\
\hline Widower & 4 & 1.1 \\
\hline
\end{tabular}


Table 2: Relationship of between socio demographic variables with QOL, perceived health and specific domains of QOL.

\begin{tabular}{|c|c|c|c|c|c|c|c|}
\hline $\begin{array}{l}\text { Socio } \\
\text { demographic } \\
\text { variables }\end{array}$ & $\begin{array}{l}\text { Correlation } \\
\text { coefficient }\end{array}$ & QOL & $\begin{array}{l}\text { Perceived } \\
\text { health }\end{array}$ & $\begin{array}{l}\text { Physical } \\
\text { domain }\end{array}$ & $\begin{array}{l}\text { Psychological } \\
\text { domain }\end{array}$ & $\begin{array}{l}\text { Environmental } \\
\text { domain }\end{array}$ & $\begin{array}{l}\text { Social } \\
\text { domain }\end{array}$ \\
\hline \multirow{2}{*}{ Age } & r value & -0.08 & 0.030 & -0.147 & -0.009 & -0.257 & -0.163 \\
\hline & $\mathrm{P}$ value & 0.126 & 0.56 & 0.005 & 0.869 & 0.001 & 0.002 \\
\hline \multirow{2}{*}{ Literacy status } & r value & 0.26 & 0.152 & 0.059 & 0.237 & 0.240 & 0.165 \\
\hline & $\mathrm{P}$ value & 0.001 & 0.003 & 0.261 & 0.001 & 0.001 & 0.001 \\
\hline \multirow{2}{*}{ Occupation } & r value & 0.09 & 0.057 & -0.073 & 0.188 & 0.068 & 0.047 \\
\hline & $\mathrm{P}$ value & 0.083 & 0.277 & 0.162 & 0.001 & 0.194 & 0.364 \\
\hline \multirow{2}{*}{$\begin{array}{l}\text { Socio economic } \\
\text { status }\end{array}$} & r value & 0.121 & 0.091 & 0.052 & 0.155 & 0.09 & 0.065 \\
\hline & $\mathrm{P}$ value & 0.02 & 0.081 & 0.316 & 0.003 & 0.082 & 0.211 \\
\hline \multirow{2}{*}{$\begin{array}{l}\text { Duration of } \\
\text { marriage }\end{array}$} & r value & -0.036 & -0.044 & 0.042 & -0.072 & 0.032 & -0.056 \\
\hline & $\mathrm{P}$ value & 0.486 & 0.397 & 0.421 & 0.167 & 0.544 & 0.287 \\
\hline \multirow{2}{*}{$\begin{array}{l}\text { Duration of } \\
\text { drinking }\end{array}$} & r value & -0.152 & -0.245 & -0.168 & -0.143 & -0.028 & 0.102 \\
\hline & $\mathrm{P}$ value & 0.003 & 0.001 & 0.001 & 0.006 & 0.591 & 0.051 \\
\hline
\end{tabular}

When duration of marriage was correlated with QOL, perceived health, physical, psychological, social and environmental domains, it showed that there was no significant relationship between all these variables and duration of marriage. Also when the duration of drinking was correlated with QOL, perceived health, physical, psychological, social and environmental domains, it showed significant negative correlation with these variables except for social and environmental domain. As the duration of drinking increased, study subjects reported poor scores in all these variables (a summary of the results are shown in Table 1 and 2).

\section{DISCUSSION}

When QOL was analyzed in relation to age, it was found that as the age of the respondents increased, fewer of them reported the QOL as good. Some of the reasons for this could be that the duration of alcohol dependence was longer in case of the older subjects in this study. This may have directly or indirectly influenced their QOL. Another reason could be that, as the age of an individual increases, burden in their family (like education of children, job responsibilities etc.) also increase. This finding was in agreement with the finding of Strandberg et al. ${ }^{14}$

When the facets of the physical, environmental and social domains were analyzed in relation to age, this study showed a significant negative correlation. As the age of the study subjects increased, fewer of them reported good scores. This could be due to the natural process of ageing. Alcohol consumption could be an added factor. This finding is in agreement with the finding of the study by Lahmek et al. $^{15}$

The literacy status of the study subjects were significantly positively correlated with QOL, perceived health, psychological, social and environmental domains. As the literacy status of the study subjects increased most of them reported good QOL. Literacy status of an individual determines various factors such as the occupation that a person will take up and also the income level. The income of a person in turn determines other factors such as housing and his living conditions. All these factors put together have a role to play in determining the QOL of an individual. Analysis of perceived health showed a significant correlation with literacy status. It was observed in this study that as the level of education increased, very few subjects reported poor health. Kerala is a state with the highest literacy rate. A higher literacy status brings with it better health awareness. In this study there were no illiterates and majority of the individuals had high school education. Good education status of the study subjects could have influenced their overall perception of health in this study.

Analysis of occupational status with QOL showed no correlation. However, majority of the professionals, officials and business men reported a good QOL, unlike the subjects in other categories. This shows that occupation of a person plays an important role in determining the QOL not only in a normal individual but also of an alcoholic individual.

When occupation was analyzed in relation to the facets of the psychological domain namely bodily image and appearance, negative and positive feelings, self-esteem, spirituality, religion, and personal beliefs, thinking, learning, memory and concentration, it showed a significant positive correlation. It was observed that majority of the subjects in each category reported good scores. Very few skilled workers and officials reported low scores as they were anxious about others at the work place being aware of their drinking habit.

Analysis of the various facets of the environmental domain namely, home environment, accessibility to and quality of health and social care, financial resources, 
freedom, physical environment, transport, physical safety and security and participation in and opportunities for recreation or leisure in relation to occupation showed that majority of the subjects in each category reported good scores. Majority of the unskilled workers however, reported low scores; their poor living conditions and other associated factors could have affected the facets of this domain.

When perceived QOL, perceived health and the four domains of the QOL namely, physical, social, psychological and environmental domains were analyzed in relation to socio economic status, a significant positive correlation was observed between socio economic status with QOL and psychological domain. A lower socio economic status implies a low earning job which in turn influences factors such as literacy, place of residence and hence the affordability and accessibility to health care, living conditions, personal relations and social support system. These factors are more likely to influence the different aspects of the QOL of an individual. Low socio economic status is one of the established socio-cultural risk factors for alcohol related problems. ${ }^{16}$

Analysis of QOL in relation to socio economic status showed a significant positive correlation. It was observed that as the socioeconomic status increased, the number of subjects reporting poor QOL decreased. Perceived health and socio economic status were not associated in the present study. However, as the socio economic status of the subjects reduced, fewer of them reported good health. This was consistent with the findings of Drummond. ${ }^{17}$

Analysis of psychological domain in relation to socio economic status showed a significant positive correlation. As the socio economic status increased, the number of subjects reporting good scores also increased.

When duration of marriage was correlated with QOL, perceived health, physical, psychological, social and environmental domains, it showed no correlation to all these variables. There was no significant relationship between all these variables and duration of marriage. When QOL was analyzed in relation to duration of marriage, it showed that as the duration of marriage increased, low scores were reported by the study subjects; which could be due to the family problems that aroused due to their drinking habit. This is in agreement with the findings of Room et al. ${ }^{18}$ Most of the unmarried subjects reported QOL to be good.

When duration of drinking was correlated with QOL, perceived health, physical, and psychological domains, it showed a significant negative correlation with these variables except for social and environmental domains. As the duration of drinking increased, study subjects reported poor scores in all these variables except in social domain. The inverse relation was found to be significant in all these variables except environmental and social domain.

When QOL was analyzed in relation to duration of drinking, it showed a significant negative correlation. As the duration of drinking in the study subjects increased more of them reported low scores. When the overall perceived health was analyzed in relation to duration of drinking, it showed a significant negative correlation. As the duration of drinking in the study subjects increased most of them reported low scores. When physical domain was analyzed in relation to duration of drinking, it showed a significant negative correlation. As the duration of drinking in the study subjects increased more of them reported low scores. When psychological domain was analyzed in relation to duration of drinking, it showed a significant negative correlation. As the duration of drinking in the study subjects increased more of them reported poor scores. All these findings were in agreement with the findings of LoCastro et al. ${ }^{19}$

When facets of the environmental domain were analyzed in relation to duration of drinking, it showed no correlation. However, it showed that as the duration of drinking in the study subjects increased more of them reported poor scores. Many of the subjects reported that when they received their salary, they would spend a major share on buying alcohol. Because of this they would have very little money left with them. They would not have much time to spend on leisure activities because they would spend most of their time drinking or working. All these factors have had an influence on this domain of the QOL of the subjects in this study.

There was no significant correlation between the facets of the social domain when analyzed in relation to duration of drinking. However it showed that as the duration of drinking in the study subjects increased, more of them reported poor scores, which could be due to the social isolation faced by the subject himself in the society, due to their drinking habit and also by negative interaction between the study subjects and their family members, relatives and friends.

\section{CONCLUSION}

Community programmes supporting healthier lifestyles, mass media campaigns that present the advantages of reduced consumption of alcohol and community development in general like job creation and skills development is the need of the hour.

\section{ACKNOWLEDGEMENTS}

We would like to convey our sincere and heartfelt thanks to Father. Thomas Thaithottam, Director, Pratheeksha deaddiction centre, Thalassery for permitting us to carry out the study in the deaddiction centre and thank all the 
patients for their untiring and whole-hearted participation in this study.

Funding: No funding sources

Conflict of interest: None declared

Ethical approval: The study was approved by the Institutional Ethics Committee

\section{REFERENCES}

1. Jernigan D. Alcohol in developing societies: a public health approach Summary. Finland: WHO Library Cataloguing-in-Publication Data; 2002: 3-27.

2. Saxena S. Country profile alcohol India. In: Leanne Riley, Mac Marshall. Alcohol and public health in eight developing countries. WHO Geneva: Substance abuse department social change and mental health; 1999. Available at: http://apapaonline.org/data/ National_Data/India/Country_Profile_Alcohol_India. pdf. Accessed on 3 June 2019.

3. Park K. Mental health. Park's textbook of preventive and social medicine. 22nd edition. Jabalpur: Banarsidas Bhanot publishers; 2013: 778.

4. Health, social and socioeconomic impact. In: Alcohol atlas of India. New Delhi: IAPA; 2008. Available at: http://www.searo.who.int/india/LinkFiles/Mental_He alth_\&_substance_Abuse_alcohol_atlas5.pdf.

Accessed on 3 June 2019.

5. Alcohol. WHO fact sheet. February, 2011. Available at: http://www.who.int/mediacentre/factsheets/ fs349/en/index.html. Accessed on 3 June 2019.

6. Global status report on alcohol and health. Switzerland: WHO library cataloguing in publication data; 2011: 1-5.

7. Gururaj G, Girish N, Benegal V. Burden and socioeconomic impact of alcohol the Bangalore study (Alcohol control series No.1). New Delhi: Macro Graphics Pvt Ltd; 2006: 3-6.

8. Gururaj G, Girish N, Benegal V, Chandra V, Pandav R. Public health problems caused by harmful use of alcohol- gaining less or losing more? (Alcohol control series No.2). New Delhi: Macro Graphics Pvt Ltd; 2006: 9-10.

9. Alcoholic beverages consumed in Kerala 2010. Available at: http://en.wikipedia.org/wiki/File: Alcoholic_beverages_consumed_in_kerala_2010. png. Accessed on 23 September 2019.

10. WHOQOL BREF Introduction, Administration, Scoring \& Generic version of the assessment. Field trial version. 1996 December. Available at: http://www.who.int/mental_health/media/en/76.pdf

11. Foster JH, Powell JE, Marshall EJ, Peters TJ. Quality of life in alcohol dependent subjects - a review. Quality of Life Research. 1999;8(3):255-61.

12. Dudala SR, Arlappa N. An updated Prasad's socioeconomic status classification for 2013. Int J Res Dev Health. 2013;1(2):26-8.

13. The ICD-10 Classification of Mental and Behavioural Disorders: Clinical descriptions and diagnostic guidelines. Available at: http://www.who. int/classifications/icd/en/bluebook.pdf. Accessed on 23 September 2019.

14. Strandberg AY, Strandberg TE, Salomaa V, Pitkala K, Miettinen TA. Alcohol consumption, 29-y total mortality, and quality of life in men in old age. Am $\mathbf{J}$ Clin Nutr. 2004;80:1366-71.

15. Lahmek P, Berlin I, Michel L, Berghout C, Meunier $\mathrm{N}$, Aubin H. Determinants of improvement in quality of life of alcohol-dependent patients during an inpatient withdrawal programme. Int $\mathrm{J}$ Med Sci. 2009;6(4):160-7.

16. Negrete JC, Gill KJ. Aetiology of alcohol problems. In: Gelder MG, Andreasen NC, Lopez-Ibor J, Geddes JR, editors. New Oxford Textbook of Psychiatry. 2nd edition, Vol.1. Italy: Oxford University Press; 2009: 432.

17. Drummond CD. The relationship between alcohol dependence and alcohol related problems in a clinical population. Br J Addiction. 1990;85:357-66.

18. Room R, Selin KH. Alcohol, gender and drinking problems perspectives from low and middle income countries. In: Obot IS, Room R, eds. China. WHO press; 2005. Available at: http://www.who.int/ substance_abuse/publications/alcohol_gender_drinki ng_problems.pdf. Accessed on 3 June 2019.

19. Locastro JS, Youngblood M, Cisler RA, Mattson ME, Zweben A, Anton RF, Donovan DM. Alcohol treatment effects on secondary nondrinking outcomes and quality of life: The COMBINE Study. J Stud Alcohol Drugs. 2009;70:186-96.

Cite this article as: Ratheesh R, Mohandas B, Venugopalan PP, Sarada AK, Suprej K, Sobith VK. Quality of life of alcohol dependent patients attending a deaddiction centre in Kannur district. Int J Basic Clin Pharmacol 2020;9:36-41. 